\title{
Investigation of the adhesion properties of calcium-phosphate coating to titanium substrate with regards to the parameters of high-frequency magnetron sputtering
}

\author{
AidAR K. KenZhegulov ${ }^{1}$, AXAUle A. MAMAeVA ${ }^{1}$, \\ ALEXANDER V. PANICHKIN ${ }^{1}$, KONSTANTIN A. PROSOLOV ${ }^{2}$, \\ ANNA BROŃCZYK ${ }^{3 *}$, DYMITRY CAPANIDIS ${ }^{3}$ \\ ${ }^{1}$ Satbayev University, Institute of Metallurgy and Ore Beneficiation, Almaty, Kazakhstan. \\ ${ }^{2}$ National Research Tomsk Polytechnic University, Tomsk, Russian Federation. \\ ${ }^{3}$ Wrocław University of Science and Technology, Faculty of Mechanical Engineering, Wrocław, Poland.
}

\begin{abstract}
Purpose: The main goal of the work was to find the interconnection between the high-frequency magnetron sputtering parameters and the adhesion properties of $\mathrm{CaP}$ coatings formed on the surface of titanium substrate. Methods: Calcium-phosphate coatings, similar in composition to hydroxyapatite, were generated by high-frequency magnetron sputtering on titanium substrate at different values of high-frequency specific power over times of one and two hours. Afterwards, the generated coatings were studied using the method of $\mathrm{X}$-ray phase analysis, and sclerometric tests (scratch test) were carried out. The adhesion strength of the deposited coatings was tested for different coating thicknesses from 0.45 to $1.1 \times 10^{-3} \mathrm{~mm}$. Results: According to the results of sclerometry, it was found that with an increase in the high-frequency specific power of plasma to $3.15 \mathrm{~W} / \mathrm{cm}^{2}$, the adhesion strength of the calcium-phosphate coating also increases. For all the coatings, the critical loads at which the coating completely exfoliated from the substrate were determined. Conclusions: According to the research results, the most optimal conditions for obtaining high-adhesive calcium-phosphate coatings were determined.
\end{abstract}

Key words: calcium-phosphate coating, high-frequency magnetron sputtering, indenter, acoustic emission, friction coefficient, titanium substrate

\section{List of abbreviations}

$\begin{array}{ll}\mathrm{AE} & - \text { acoustic emission } \\ \mathrm{CoF} & - \text { coefficient of friction } \\ \mathrm{DP} & - \text { depth of penetration } \\ \mathrm{FF} & - \text { friction force } \\ \mathrm{HA} & - \text { hydroxyapatite } \\ \mathrm{HFMS} & - \text { high-frequency magnetron sputtering } \\ L_{c} & - \text { critical load } \\ \text { Si-HA } & - \text { silicon-doped hydroxyapatite-based }\end{array}$

\section{Introduction}

One of the rapidly developing areas of modern medical materials science is the creation of new materials for implants to replace damaged tissue sites [8], [12]. The problem of the biocompatibility of materials is a matter of great importance in medical materials science. To increase the biocompatibility of implants,

\footnotetext{
* Corresponding author: Anna Brończyk, Wrocław University of Science and Technology, Faculty of Mechanical Engineering, ul. Łukasiewicza 5, 50-370 Wrocław, Poland. Phone: +48 71320 4053, e-mail: anna.bronczyk@pwr.edu.pl

Received: January 15th, 2020

Accepted for publication: April 16th, 2020
} 
additional coatings [7], [11] and surface modifications [10], [14] are applied to their surface. There has been a recent growth in interest regarding calcium-phosphate $(\mathrm{CaP})$ and hydroxyapatite $\mathrm{Ca}_{10}\left(\mathrm{PO}_{4}\right)_{6}(\mathrm{OH})_{2}(\mathrm{HA})$ coatings, which significantly increase the adhesive strength of implants with bone tissue [5], [19], [22].

To date, a wide range of methods, developed and tested to create $\mathrm{CaP}$ coatings on metal implants, have been used: the plasma spraying process [18], microarc oxidation [1], methods based on the crystallization of coatings from various solutions [25], the method of detonation-gas spraying [17], electrochemical deposition [2], the sol-gel process [2], [4], etc. Each of the listed methods has its own advantages and disadvantages.

Coatings for medical implants have strict requirements. Ideal for these purposes is a coating with low porosity (but sufficient for integration with bone tissue), high adhesive strength, chemical stability, and phase composition, which all help to ensure the biocompatibility of the coating [23]. First of all, the coating should have high adhesion to the substrate to ensure its high practicality [13]. In accordance with current research, the use of the high-frequency magnetron sputtering (HFMS) method provides high adhesive strength between the substrate and the coating. Under optimal experimental conditions, the coatings are close and in stoichiometric composition to the initial target's composition [16].

One of the most important characteristics of $\mathrm{CaP}$ coatings is their strength. To evaluate the adhesion strength of coatings and their physico-mechanical properties, the method of sclerometry (scratch test) is applied [20]. The sclerometry method is a simple, semi-quantitative method that can be used to measure the adhesion strength of various substrate-coating systems. It includes the application of a normal load on the sample surface through an indenter that moves across the surface of the sample at a constant speed [24]. The sclerometry method makes it possible to identify the critical load on the coating, at which the film breaks down and exfoliation from the substrate starts to proceed.

The preliminary preparation of the substrate surface prior to deposition is important for high adhesion, since its purity determines the level of chemical bonding at the coating-substrate interface. In [15], the authors investigated the effect of heat treatment of biocomposites on their structure, morphology, and, in particular, their adhesive properties. To determine the scratch resistance and the mechanism of destruction of $\mathrm{CaP}$ coatings, sclerometry was used with an increasing load from 0.9 to $5 \mathrm{~N}$. It was established that the coatings had high wear resistance and adhesion. Silicon-doped hydroxyapatite-based (Si-HA) coatings 400-700 nm thick, deposited at different values of the bias potential on the substrate, were subjected to the scratch test [20]. It was found that the use of negative potential in the deposition process of Si-HA coatings by HFMS leads to a decrease in the adhesive strength of the coatings. The authors of [3], [9] investigated the mechano-tribological properties of $\mathrm{CaP}$ coatings on titanium and its alloys with regards to the thickness of film. As a result, it was found that scratch resistance on the surface improves with an increasing coating thickness, in particular above $720 \mathrm{~nm}$ [9] and $1000 \mathrm{~nm}$ [3]. In [6], thin CaP coatings were deposited on titanium substrates using a HFMS HA target in the atmosphere of different gases: in neon (Ne), argon (Ar), krypton (Kr), and xenon (Xe). The coating obtained in Xe was completely amorphous and had the highest adhesion to the substrate.

Despite the fact that a lot of research has been done in this area, the interconnection between the HFMS parameters and the adhesion characteristics of the forming layer is still relevant. This is due to the lack of systematic information on the effect of sputtering parameters on the properties of $\mathrm{CaP}$ coatings. Thus, in the present experimental study, the effect of the specific power and deposition time of magnetron sputtering on the adhesive properties of $\mathrm{CaP}$ coatings to the titanium substrate VT1-0 brand was studied.

\section{Materials and methods}

This study contains the following actions/stages: preliminary preparation of the substrates, coating deposition, coating thickness measurements, phase composition analysis and sclerometric tests.

The first stage consists of the preliminary preparation of the titanium plates (VT1-0 brand) used as the coating substrates. The preliminary preparation involves the cleaning of various organic and inorganic pollutants. At first, grinding with abrasive papers (P120, P320, P600, P1200, P2500, P3000) and polishing with diamond paste were carried out. Circles made of 'drape' material are mounted on the polishing machine. ASM grade diamond paste with a grain size of $60 / 40,5 / 3,2 / 1$ was applied onto its surface. In this order, sequential polishing of the titanium substrate was carried out. Then, the titanium substrates were washed with distilled water for $10 \mathrm{~min}$ and degreased with ethanol. Cleaning with ethanol was carried out in an ultrasonic bath for 20 minutes at a temperature of 


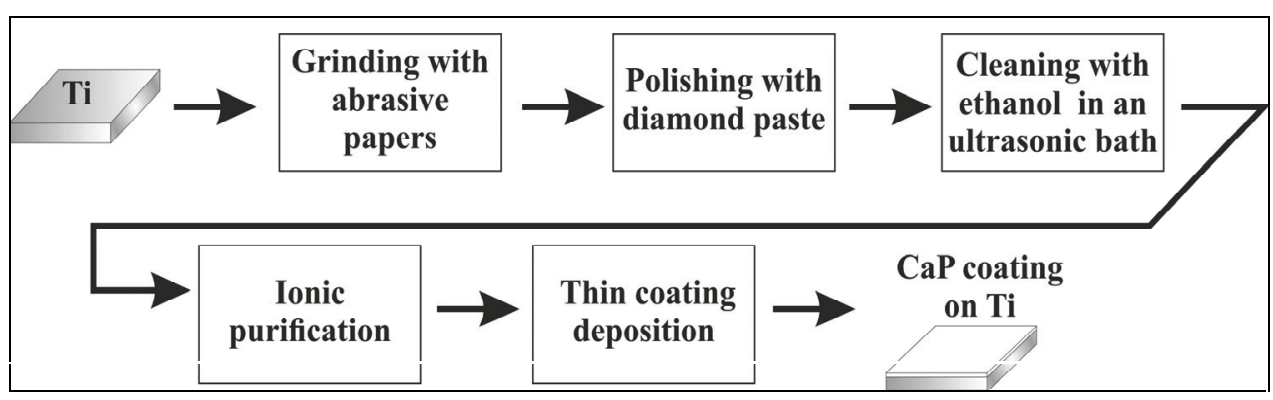

Fig. 1. Scheme of the substrates preparation and coating deposition

$50{ }^{\circ} \mathrm{C}$, after which the samples were dried at room temperature. After performing the mentioned processes, ionic purification was performed at a voltage of $2.5 \mathrm{kV}$ and $37 \mathrm{~mA}$. The last step was the deposition of the thin layer of the HA target on the substrate's surface (Fig. 1).

For the deposition of the CaP coatings, a modernized vacuum setup with a magnetron source was used. The operating frequency of the high-frequency generator was 13.56 MHz. The target was a disc with a diameter of $110 \mathrm{~mm}$ made from compressed HA powder. The dispersion of HA particles was less than $5 \mu \mathrm{m}$. As the operating gas, argon was applied. Moreover, the following coating deposition modes were employed: the working pressure in the chamber after argon injection was equal to $0.1 \mathrm{~Pa}$, the distance between the target and the substrate was equal to $68 \mathrm{~mm}$, the specific discharge power of the plasma was $2.10,2.63,3.15,3.68 \mathrm{~W} / \mathrm{cm}^{2}$, and the deposition time was one and two hours.

The measurement of the thickness of the obtained $\mathrm{CaP}$ coatings deposited on the titanium substrate was carried out using scanning electron microscopy (JXA-8230, JEOL, USA), which measured the crosssection of the coatings. The coating thickness was measured at an accelerating voltage of $20 \mathrm{kV}$ and with an electron beam current of $7 \mathrm{nA}$.

The phase composition analysis of the obtained coatings was studied using a diffractometer (D8 Advance Diffractometer, Bruker, USA) at the Kazakhstan National Laboratory of Collective Use of the Institute of Metallurgy and Ore Beneficiation.

High adhesion of the coating to the surface of the implant is one of the basic requirements for the longterm functioning of coated implants. Previously, we reported the adhesion properties of $\mathrm{CaP}$ coatings deposited by HF magnetron sputtering on Ti [9], [15]. We found that the adhesion strength of the coatings to the substrate depends on the coating thickness and on the heat treatment temperature. In the present work, the influence of the deposition parameters on the adhesion of coatings was investigated. First, $\mathrm{CaP}$ coatings obtained at a deposition time of 1 hour were investigated. To study the adhesive characteristics, the sclerometric method was applied. The adhesive properties of the $\mathrm{CaP}$ coatings were measured using a scratch tester (REVETEST, CSM Instruments, Switzerland) with an optical microscope and scanning electron microscope (Quanta 200 3D, FEI, USA). The parameters of the scratch test were: maximum load $-10 \mathrm{~N}$, the changing rate of the normal load on the sample $-1 \mathrm{~N} / \mathrm{min}$, the speed of movement of the indenter $-0.5 \mathrm{~mm} / \mathrm{min}$, scratch length $-5 \mathrm{~mm}$, the radius of the tip curvature $-20 \mu \mathrm{m}$. During the scratching of the coating surface, the scratch tester recorded the following physical parameters: normal force (load on the indenter), acoustic emission (AE), coefficient of friction (CoF), force of friction (FF), and depth of penetration (DP) of the indenter. These results were monitored using an integrated Revetest optical microscope. Regarding the length of the scratch, dependency graphs were prepared. In order to compare the adhesion characteristics of all the coatings, the maximum load on the indenter was equal to $10 \mathrm{~N}$. This was chosen as it was the average load at which no exfoliating of the coating was observed. As a result of the tests, the minimum critical load that led to the destruction of the coating was determined. The moment of adhesive destruction of the coating occurs with a sharp increase in acoustic emission and coefficient of friction.

Processing the results of dependencies was carried out using the OriginPro 8.1. and Coreldraw X7 programs.

\section{Results}

Selected results of the CaP coating thickness measurements and its dependence on the specific power of the plasma at different deposition times as well as the picture of the surface of the titanium substrate after machining process and after the deposition of the HA target are presented in Fig. 2.

Collective results of the phase composition measurements are presented in Fig. 3. 

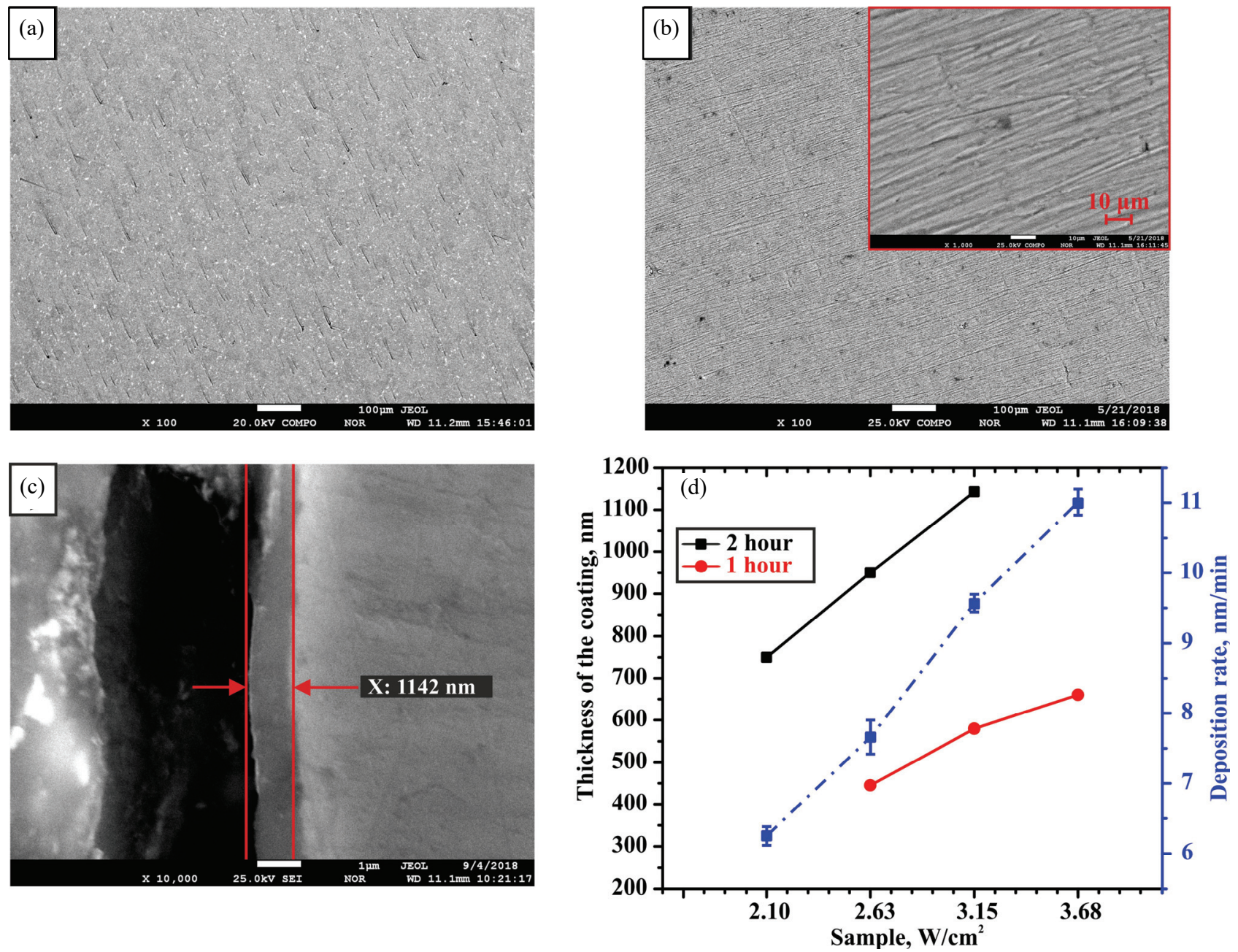

Fig. 2. The surface of the titanium substrate after machining process (a) and after the deposition of the HA target (b), the thickness of the coating deposited at a specific plasma power of $3.15 \mathrm{~W} / \mathrm{cm}^{2}$ (c) and the dependence of the thickness and deposition rate of the coating on the specific power of the plasma at different deposition times (d)
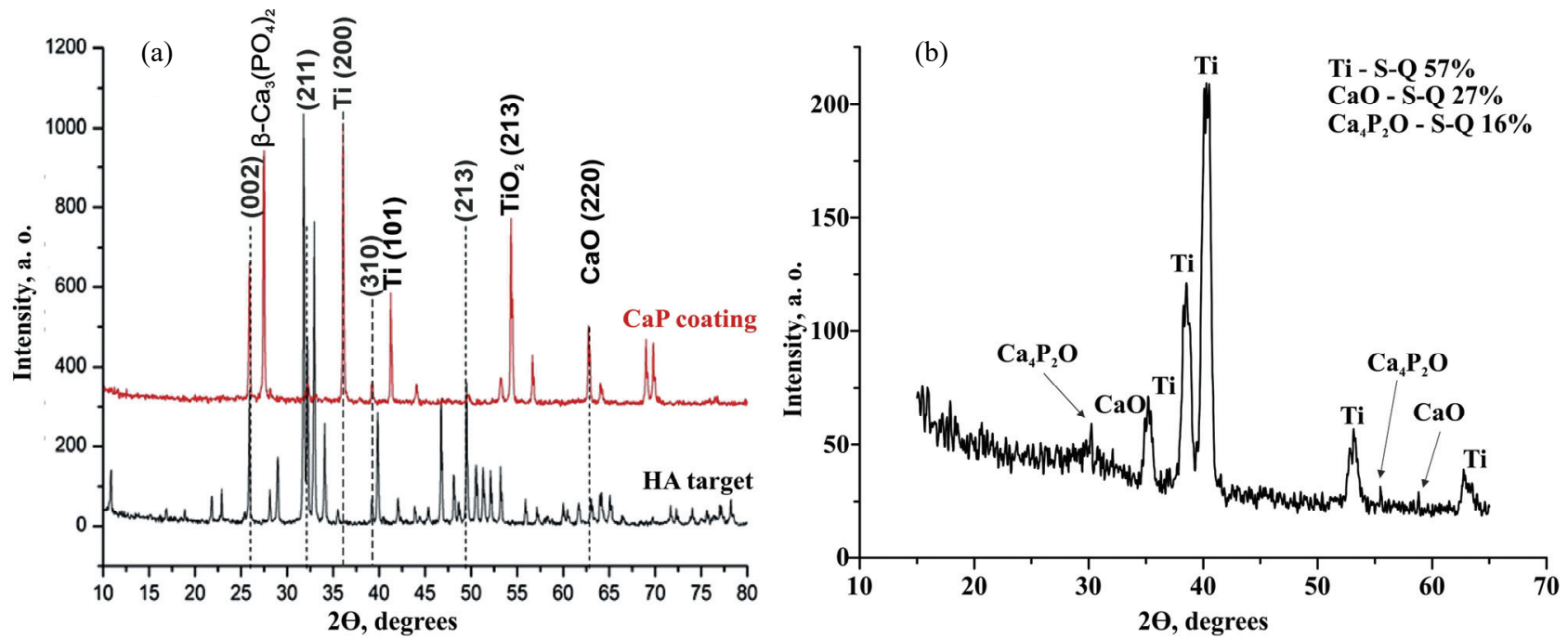

Fig. 3. X-ray diffraction patterns of the HA target and CaP coating deposited at a specific power of $2.63 \mathrm{~W} / \mathrm{cm}^{2}$ (a) and $3.15 \mathrm{~W} / \mathrm{cm}^{2}$ (b) 

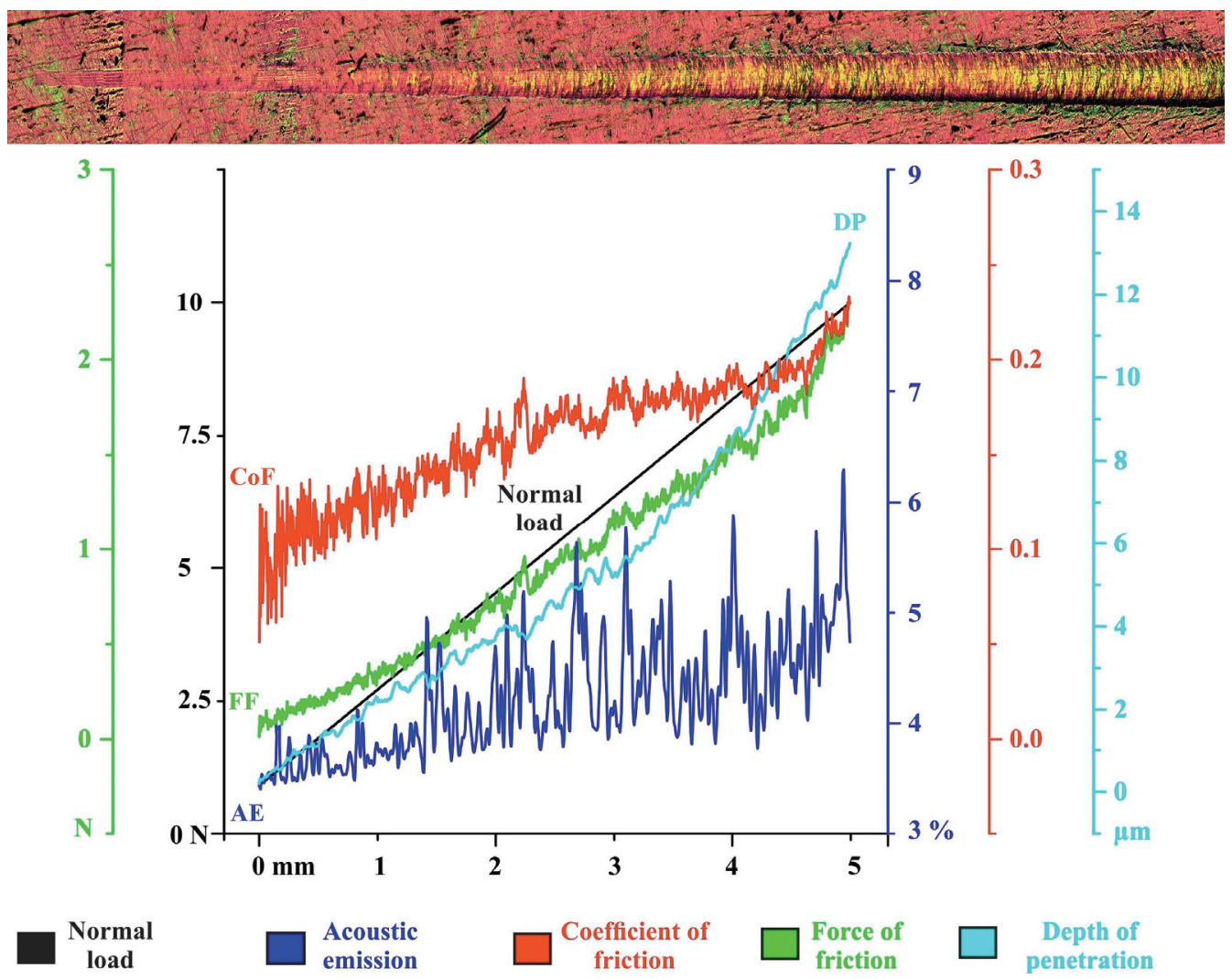

Fig. 4. Results of the scratch test of the CaP coatings obtained at a specific power of sputtering of $2.63 \mathrm{~W} / \mathrm{cm}^{2}(1 \mathrm{hour})$
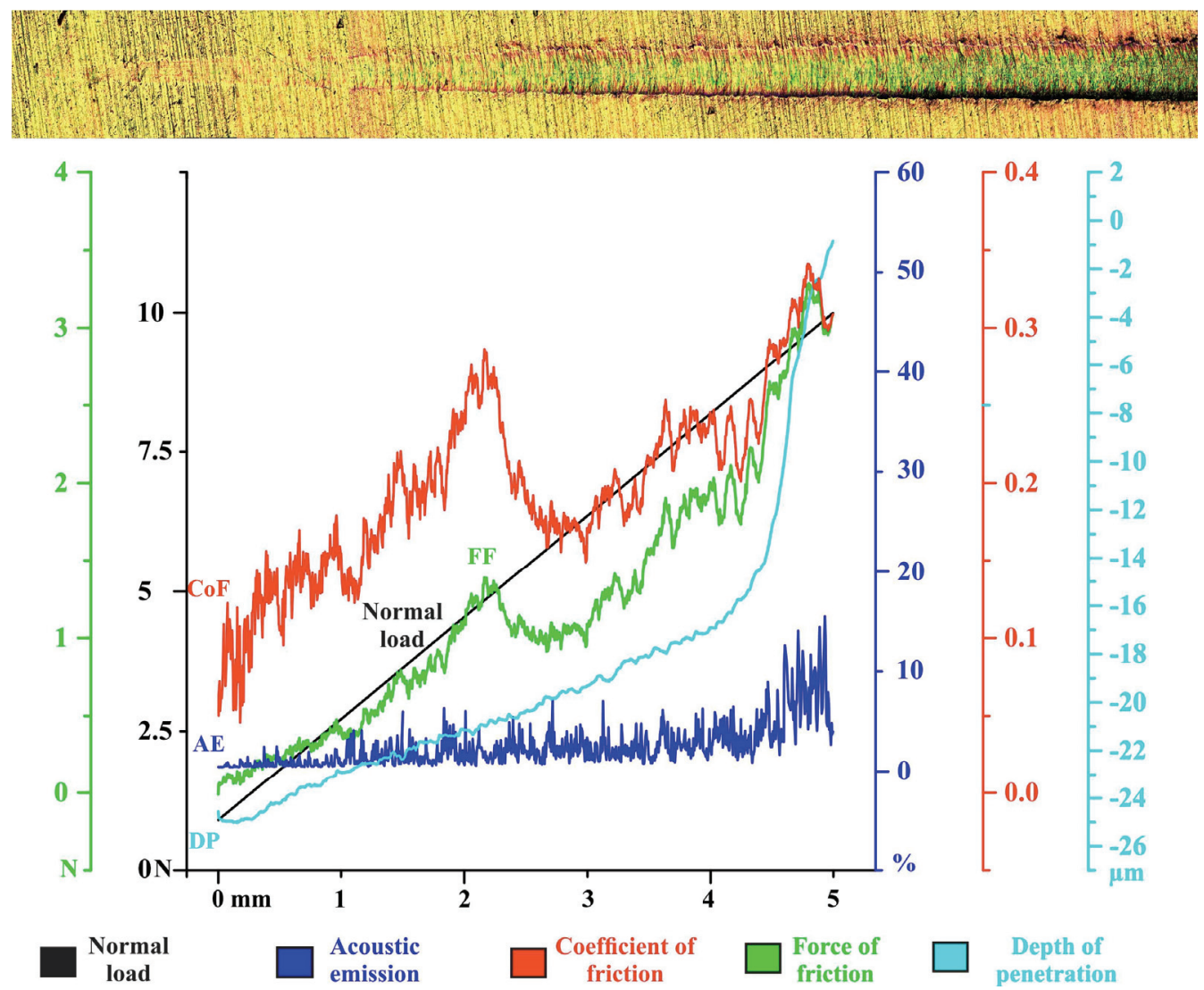

Fig. 5. Results of the scratch test of the CaP coatings obtained at a specific power of sputtering of $3.15 \mathrm{~W} / \mathrm{cm}^{2}(1$ hour $)$ 

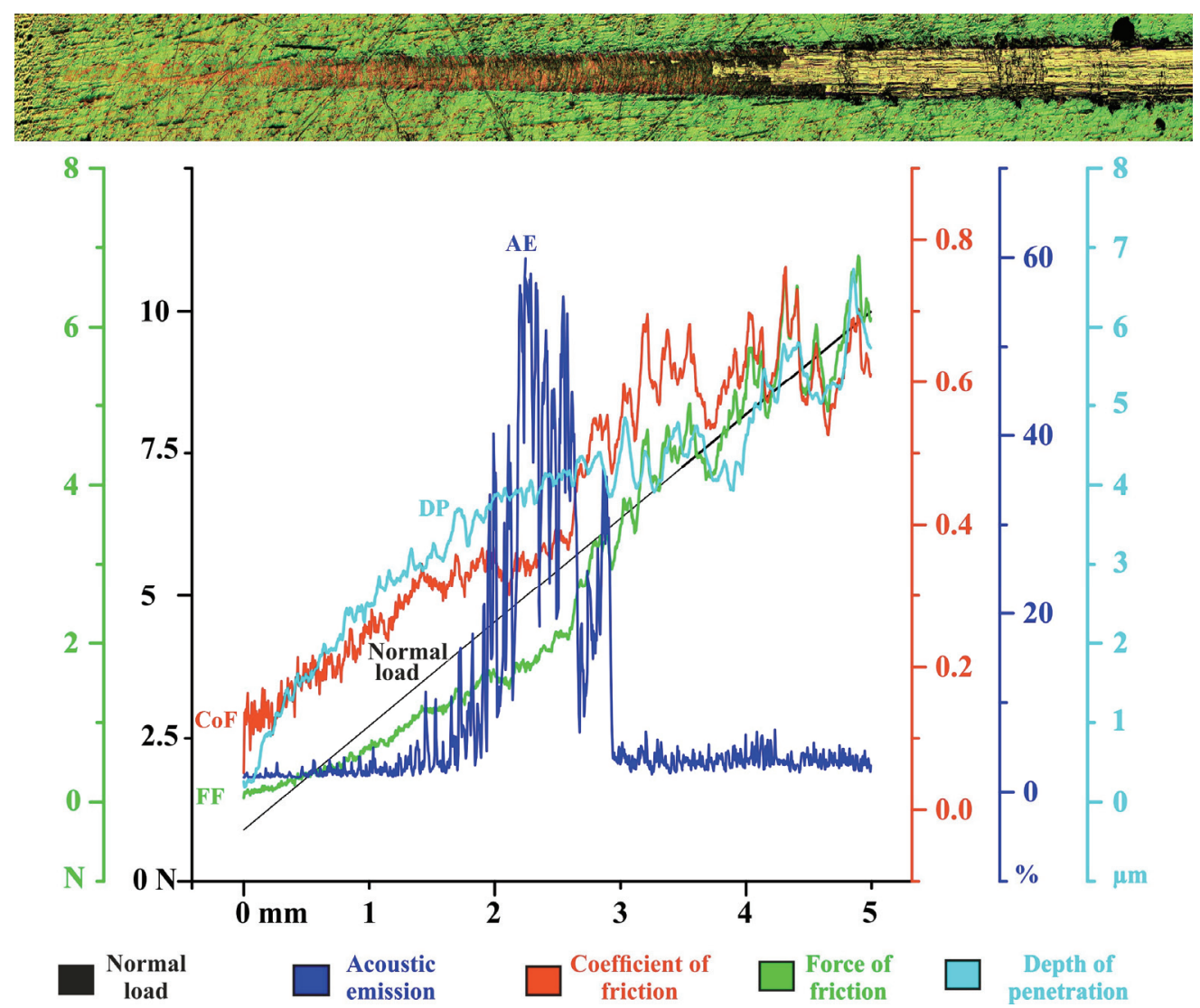

Fig. 6. Results of the scratch test of the CaP coatings obtained at a specific power of sputtering of $3.68 \mathrm{~W} / \mathrm{cm}^{2}$ (1 hour)
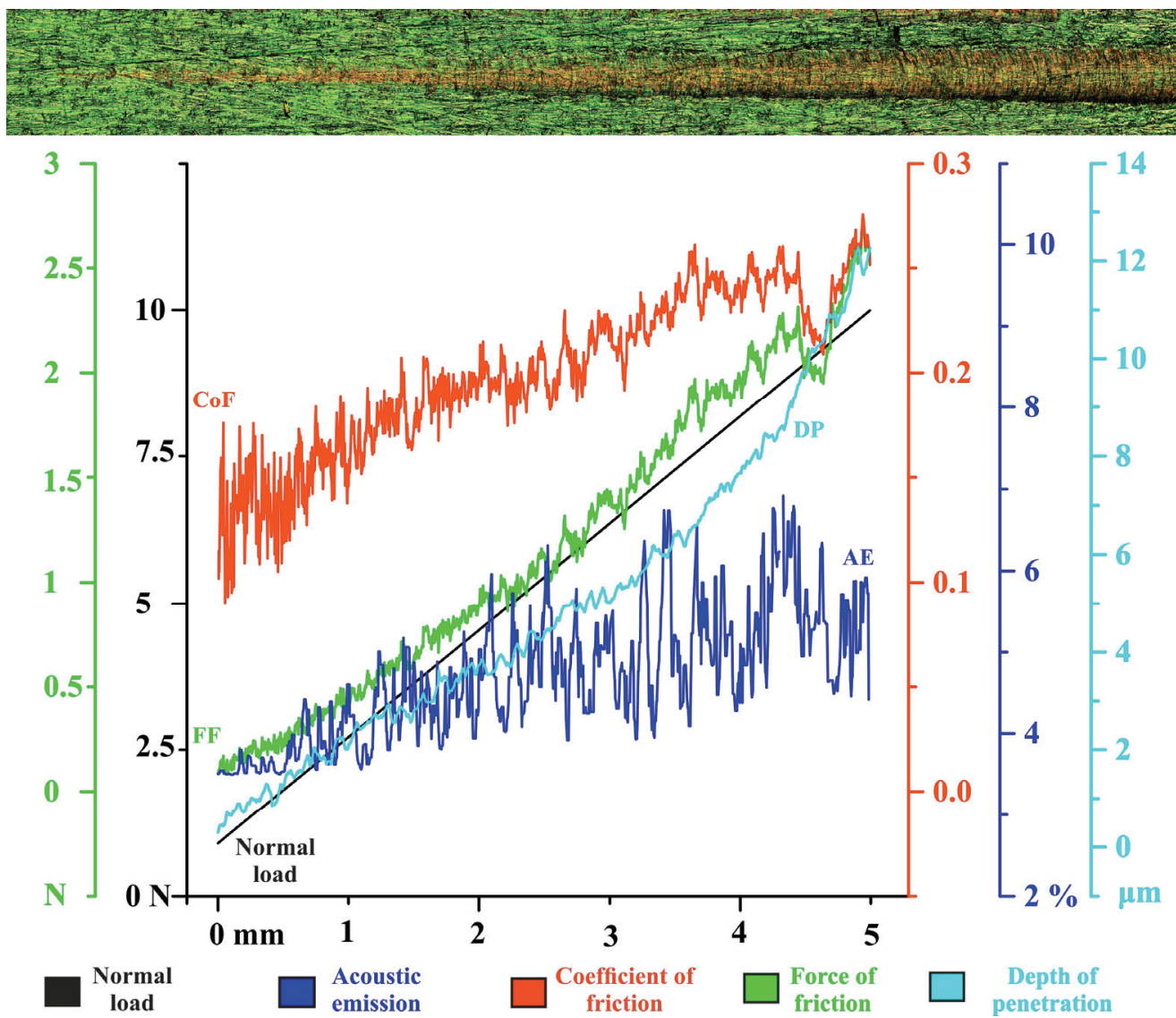

Fig. 7. Results of the scratch test of the CaP coatings obtained at a specific power of sputtering of $2.10 \mathrm{~W} / \mathrm{cm}^{2}(2 \mathrm{hours})$ 

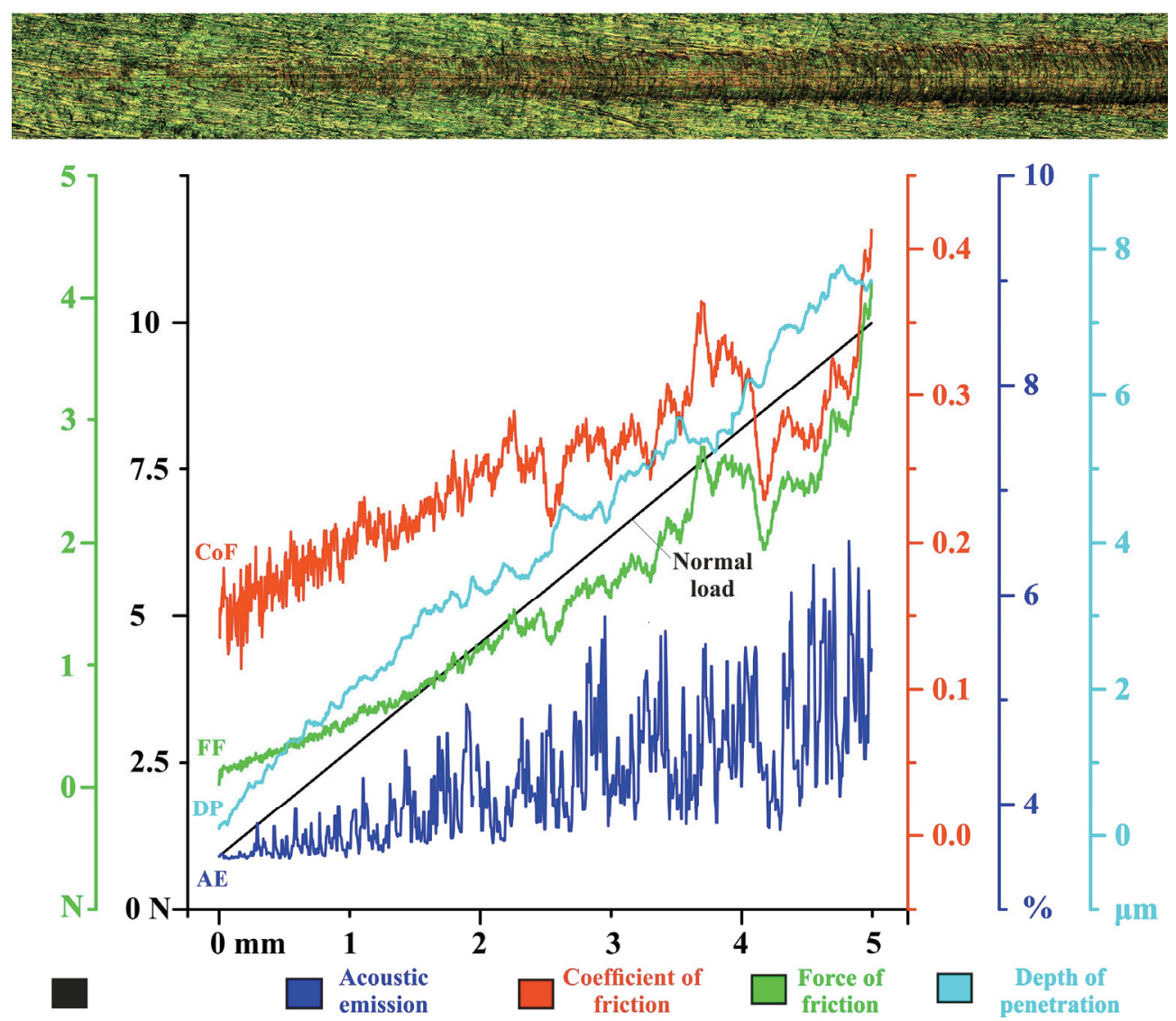

Fig. 8. Results of the scratch test of the $\mathrm{CaP}$ coatings obtained at a specific power of sputtering of $2.63 \mathrm{~W} / \mathrm{cm}^{2}$ (2 hours)

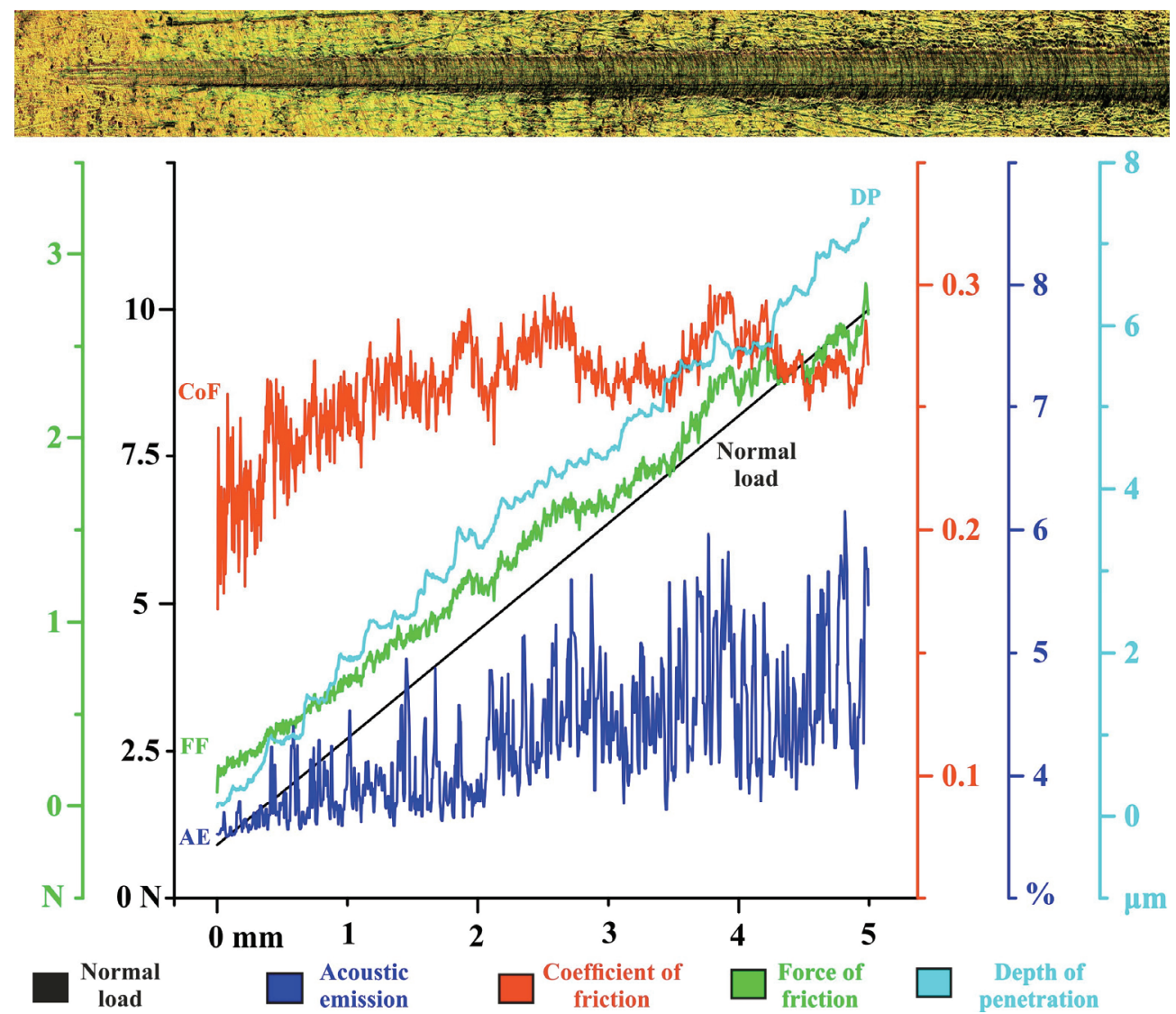

Fig. 9. Results of the scratch test of the CaP coatings obtained at a specific power of sputtering of $3.15 \mathrm{~W} / \mathrm{cm}^{2}$ (2 hours) 
The main adhesion characteristics of the $\mathrm{CaP}$ coatings, obtained at a specific power of $2.63,3.15$, and $3.68 \mathrm{~W} / \mathrm{cm}^{2}$ for 1 hour, as well as the optical images of the scratches after the test, are presented in Figs. 4-6.

The next series of sclerometric studies was carried out for coatings deposited at a specific plasma power of $2.10,2.63$, and $3.15 \mathrm{~W} / \mathrm{cm}^{2}$ for 2 hours. The main adhesion characteristics of the $\mathrm{CaP}$ coatings and the optical micrographs of the scratches from this study are presented in Figs. 7-9.

\section{Discussion}

Figure $2 \mathrm{~d}$ shows the experimental dependences of the thickness and deposition rate of the coating on the specific power of the plasma discharge at a deposition time of 1 and 2 hours. Optimal conditions for HFMS were experimentally determined: plasma power from 2.10 to $3.68 \mathrm{~W} / \mathrm{cm}^{2}$ (sputtering time 1 and 2 hours). At plasma power of $2.10 \mathrm{~W} / \mathrm{cm}^{2}$ (1 hour), a formed $\mathrm{CaP}$ layer was very thin (below $0.4 \mu \mathrm{m}$ ) and it was excluded from the graph (Fig. 2d). Unfortunately, the coating formed with the plasma power of $3.68 \mathrm{~W} / \mathrm{cm}^{2}$ (2 hours) was not successful as well. Large plasma power and a long deposition time lead to thermal destruction of the coating. For these reasons, it was not possible to obtain the dependences in the graphic image for coatings formed at a plasma power of $2.10 \mathrm{~W} / \mathrm{cm}^{2}$ (1 hour) and $3.68 \mathrm{~W} / \mathrm{cm}^{2}$ ( 2 hours). In general, it was determined that the dependence of the thickness and deposition rate of the coating on the specific plasma power is characterized by a linear or semi-linear growth.

The X-ray diffraction pattern of the HA target and the obtained $\mathrm{CaP}$ coating (Fig. 3a) reveals the presence of the following compounds and element peaks: $\mathrm{Ca}_{10}\left(\mathrm{PO}_{4}\right)_{6}(\mathrm{OH})_{2}, \mathrm{Ti}, \mathrm{CaO}, \mathrm{TiO}_{2}$ and $\beta-\mathrm{Ca}_{3}\left(\mathrm{PO}_{4}\right)_{2}$. On the diffractograms there are reflexes at 25.890 (002), 34.050 (202), and 49.470 (213), corresponding to the HA, Ti (200), (101), calcium oxide (220) and titanium oxide (213). The diffraction lines corresponding to the HA are shifted toward larger angles, and accordingly, the value of the interplanar distances decreases, which, as described in [6], is due to the formation of tricalcium phosphate and titanium oxide. In the sample obtained at a specific power of $3.15 \mathrm{~W} / \mathrm{cm}^{2}$, there are phases corresponding to $\mathrm{Ca}_{4} \mathrm{P}_{2} \mathrm{O}, \mathrm{CaO}$, and $\mathrm{Ti}$ (Fig. $3 b)$. The percentage content of the phases is: $\mathrm{Ca}_{4} \mathrm{P}_{2} \mathrm{O}$ $-16 \%, \mathrm{CaO}-27 \%$, and $\mathrm{Ti}-57 \%$. Thus, as a result of using the HFMS method, crystalline $\mathrm{CaP}$ coatings, which are similar in phase composition to HA, are obtained on the titanium substrate surface. Calciumphosphate compounds and oxide calcium and titanium oxide are also obtained on the titanium substrate surface.

As can be seen from the micrographs, the coatings obtained at $2.63 \mathrm{~W} / \mathrm{cm}^{2}$ (Fig. 4) and $3.15 \mathrm{~W} / \mathrm{cm}^{2}$ (Fig. 5) do not demonstrate the destruction and exfoliation of the coatings along the scratch of the diamond indenter, which indicates a high adhesion of the coating to the titanium substrate. For them, even with a load of $10 \mathrm{~N}$, the acoustic emission was in the range of $0-15 \%$, and the coefficient of friction was $0-0.3$. Small variations in the acoustic emission in the initial test stage with a very low applied load are due to the surface roughness of the coatings, as reported in [21]. On the contrary, the sample obtained with a maximum power density of $3.68 \mathrm{~W} / \mathrm{cm}^{2}$ (Fig. 6) exhibits flaking of the coating, which is accompanied by a sharp increase in the acoustic emission on the graph. This confirms the start of the coating destruction process. The coefficient of friction, during the scratch test, exhibits an increase to 0.8 . Coating exfoliation from the titanium substrate occurs at a load of $4.3 \mathrm{~N}$, which can also be seen in the optical image of the scratch (Fig. 6). Thus, according to the analysis of the adhesion characteristics of the $\mathrm{CaP}$ coatings, the maximum value of the specific power of the plasma does not lead to the formation of high adhesion $\mathrm{CaP}$ coatings.

All three coatings revealed high adhesion strengths, and the coating does not even break at a maximum load of $10 \mathrm{~N}$, as presented in the microphotographs. The depth of penetration of the indenter varied within 8-14 $\mu \mathrm{m}$, which means a high $\mathrm{CaP}$ coating hardness. The samples revealed low values of friction coefficient during the scratch test - about 0.4.

On the sample obtained at $2.10 \mathrm{~W} / \mathrm{cm}^{2}$, the separation of the coating is not observed, even for the maximal load of $10 \mathrm{~N}$ (Fig. 7). However, when increasing the load to the maximum, there is an influx of material near the end of the track. This indicates its high cohesion value, which characterizes the adhesion strength of the coating [16]. In the case of the coating obtained at $2.63 \mathrm{~W} / \mathrm{cm}^{2}$ (Fig. 8), cracking is observed in the early stages of loading. The colour change (at the end of the scratch) is due to the partial coating exfoliation and changes in the interference conditions on thin films. When the specific power is increased to $3.15 \mathrm{~W} / \mathrm{cm}^{2}$, the picture changes weakly, and stresses and cracks are still visible. However, such 'extrusion' of the material is not observed (Fig. 9). Moreover, a hard coating is formed, which is characterized by the formation of minimal defects along the scratch length. 
According to the sclerometry results, it can be noted that the samples obtained at relatively high specific sputtering powers (up to $3.15 \mathrm{~W} / \mathrm{cm}^{2}$ ) have a high adhesion to the substrate and low coefficient of friction (up to 0.4). This is a consequence of the formation of strong chemical bonds between the $\mathrm{CaP}$ coating and the substrate.

$L_{c}$ is the value of the critical load at the point where the deposited coating begins to detach from the substrate [20]. For all the coatings, the critical load $L_{c}$, at which the coating completely exfoliates off the substrate, was higher than $12.6 \mathrm{~N}$, with the exception of the coating obtained at $3.68 \mathrm{~W} / \mathrm{cm}^{2}$ (1 hour), for which it was equal to $4.3 \mathrm{~N}$. Some local tears of the coating were observed along the edge of the groove for scratches under high normal load.

Thus, CaP coatings, deposited at a specific power of $2.10,2.63$, and $3.15 \mathrm{~W} / \mathrm{cm}^{2}$ ( 1 and 2 hours) and with thicknesses from 0.45 to $1.1 \mu \mathrm{m}$, have the highest adhesive strength.

\section{Conclusions}

An analysis of the experimental results of the structure and properties of $\mathrm{CaP}$ coatings was carried out. It was established that sputtering at a specific power of the magnetron plasma of $2.10 \mathrm{~W} / \mathrm{cm}^{2}$ forms a coating on the crystal structure closest to HA. An increase in power to 3.15 or $3.68 \mathrm{~W} / \mathrm{cm}^{2}$ leads to the formation of predominantly $\mathrm{CaP}$ compounds. Adhesion and tribological tests using the sclerometry method, in which the threshold values of the critical load are determined, made it possible to determine the adhesive strength with regards to the HFMS parameters. For all the coatings, the critical load $L_{c}$, at which the coating completely exfoliates off the substrate, was higher than $12.6 \mathrm{~N}$, except for the coating obtained at $3.68 \mathrm{~W} / \mathrm{cm}^{2}$ ( 1 hour), for which $L_{c}$ was equal to $4.3 \mathrm{~N}$. The highest adhesive strength was observed for the $\mathrm{CaP}$ coatings formed at a specific power of 2.10, 2.63 , and $3.15 \mathrm{~W} / \mathrm{cm}^{2}$, for both 1 and 2 hours, with thicknesses from 0.45 to $1.1 \mu \mathrm{m}$.

The boundary thickness $(0.45-1.1) \mu \mathrm{m}$ was determined at which the nature of the mechanical destruction of the coating changes. Coatings with a thickness of less than $1.6 \mu \mathrm{m}$ provide the optimal combination of cohesive strength and adhesion of coatings to VT1-0 titanium substrates.

Thus, as a result of the research, optimal experimental regimes and parameters were determined for obtaining good quality high-adhesion $\mathrm{CaP}$ coatings.
The obtained coatings may be promising for thin-film materials used in medicine for various types of elements supporting osseointegration, for example: plates for connecting bone fragments, spine implants and tooth fillings [15].

\section{Acknowledgements}

The work was carried out with partial financial support of the grants of the Science Committee of the Ministry of Education and Science of the Republic of Kazakhstan (No. AP05130722).

\section{References}

[1] Alsaran A., Purcek G., Hacisalihoglu I., Vangolu Y., BAYRAK Ö., KARAMAN I., CeliK A., Hydroxyapatite production on ultrafine-grained pure titanium by micro-arc oxidation and hydrothermal treatment, Surf. Coatings Technol., 2011, 205, S537-S542.

[2] AsRi R.I.M., HaRun W.S.W., Hassan M.A., GHANi S.A.C., BuYONG Z., A review of hydroxyapatite-based coating techniques: Sol-gel and electrochemical depositions on biocompatible metals, J. Mech. Behav. Biomed. Mater., 2016, 57, 95-108.

[3] Behera R.R., Das A., Pamu D., Pandey L.M., Sankar M.R., Mechano-tribological properties and in vitro bioactivity of biphasic calcium phosphate coating on Ti-6Al-4V, J. Mech. Behav. Biomed. Mater., 2018, 86, 143-157.

[4] Catauro M., Papale F., Sapio L., Naviglio S., Biological influence of $\mathrm{Ca} / \mathrm{P}$ ratio on calcium phosphate coatings by sol-gel processing, Mater. Sci. Eng. C., 2016, 65, 188-193.

[5] ChandRamohan D., MaRimuthu K., Characterization of natural fibers and their application in bone grafting substitutes, Acta Bioeng. Biomech., 2011, 13.

[6] Fedotkin A.Y., Bolbasov E.N., Kozelskaya A.I., DubINENKo G., SHESTERIKOV E.V., Ashrafov A., TVERDOKHLEBOV S.I., Calcium phosphate coating deposition by radio frequency magnetron sputtering in the various inert gases: The pilot study, Mater. Chem. Phys., 2019, 121735.

[7] GrYgier D., DudziŃSKi W., RutKowsKa-GorcZYCA M., The perspective of sol-gel technology in the development of coatings on medical implants, Eng. Biomater., 2010, 13.

[8] Jin S., Zhang Y., Wang Q., Zhang D., Zhang S., Influence of TiN coating on the biocompatibility of medical NiTi alloy, Colloids Surfaces B. Biointerfaces, 2013, 101, 343-349.

[9] KenZhegulov A.K., Mamayeva A.A., PanichKin A.V., Adhesion properties of calcium-phosphate coatings on titanium, J. Complex use of mineral resources, 2017, 3, 35-41 (in Russian).

[10] Kobielarz M., Gazińska M., Tomanik M., StęPaK B., Szustakiewicz K., Filipiak J., AntończaK A., Pezowicz C., Physicochemical and mechanical properties of $\mathrm{CO}_{2}$ lasermodified biodegradable polymers for medical applications, Polym. Degrad. Stab., 2019, 165, 182-195.

[11] Krzak-Roś J., Filipiak J., Pezowicz C., Baszczuk A., Miller M., Kowalski M., BĘDZIŃSKI R., The effect of substrate roughness on the surface structure of $\mathrm{TiO}_{2}, \mathrm{SiO}_{2}$, and doped thin films prepared by the sol-gel method, Acta Bioeng. Biomech., 2009, 11, 21-29. 
[12] Kucharczyk A., Naplocha K., TomaniK M., Processing of porous NiTi preforms for NiTi/Mg composites, Arch. Metall. Mater., 2019, 64, 747-752.

[13] LaCefield W.R., Hydroxylapatite coatings, [in:] Introd. to Bioceram., World Scientific, 1993, 223-238.

[14] ŁęCKA K.M., ANTOŃCZAK A.J., KOWALEWSKI P., TRZCiŃSKI M., Wear resistance of laser-induced annealing of AISI 316 (EN 1.4401) stainless steel, Laser Phys., 2018, 28, 096005. https://doi.org/10.1088/1555-6611/aac507.

[15] Mamaeva A., Kenzhegulov A., Kowalewski P., Wieleba W., Investigation of hydroxyapatite-titanium composite properties during heat treatment, Acta Bioeng. Biomech., 2017, 19. https://doi.org/10.5277/ABB-00800-2016-04.

[16] Pichugin V.F., SuRMENeV R.A., SheSterikov E.V., Ryabtseva M.A., Eshenko E.V., TVerdokhlebov S.I., PRYMAK O., EPPle M., The preparation of calcium phosphate coatings on titanium and nickel--titanium by rfmagnetron-sputtered deposition: composition, structure and micromechanical properties, Surf. Coatings Technol., 2008, 202, 3913-3920.

[17] Singh L., Chawla V., Grewal J.S., A review on detonation gun sprayed coatings, J. Miner. Mater. Charact. Eng., 2012, $11,243$.

[18] Su Y., Li K., Zhang L., Liu S., Yuan Y., He S., Calcium phosphorus bio-coating on carbon/carbon composites: preparation, shear strength and bioactivity, Appl. Surf. Sci., 2017, 419, 503-511.

[19] Sun L., Berndt C.C., Gross K.A., KuCuK A., Material fundamentals and clinical performance of plasma-sprayed hydroxyapatite coatings: A review, J. Biomed. Mater. Res. An Off.
J. Soc. Biomater. Japanese Soc. Biomater. Aust. Soc. Biomater. Korean Soc. Biomater., 2001, 58, 570-592.

[20] Surmeneva M.A., Sharonova A.A., Chernousova S., Prymak O., Loza K., TKachev M.S., Shulepov I.A., Epple M., SURMENEV R.A., Incorporation of silver nanoparticles into magnetron-sputtered calcium phosphate layers on titanium as an antibacterial coating, Colloids Surfaces B. Biointerfaces, 2017, 156, 104-113.

[21] Surmeneva M.A., MukhametKaliyev T.M., Tyurin A.I., Teresov A.D., Koval N.N., PirozhKova T.S., Shuvarin I.A., SHuKlinOV A.V., ZHIGACHEV A.O., OEHR C. et al., Effect of silicate doping on the structure and mechanical properties of thin nanostructured RF magnetron sputter-deposited hydroxyapatite films, Surf. Coatings Technol., 2015, 275, 176-184.

[22] Trybuś B., Zieliński A., Beutner R., SeramaK T., SCHARnweber D., Deposition of phosphate coatings on titanium within scaffold structure, Acta Bioeng. Biomech., 2017, 19.

[23] Tsui Y.C., Doyle C., Clyne T.W., Plasma sprayed hydroxyapatite coatings on titanium substrates, Part 1: Mechanical properties and residual stress levels, Biomaterials, 1998, 19, 2015-2029.

[24] Valli J., Mäkelä U., Matthews A., Murawa V., TiN coating adhesion studies using the scratch test method, J. Vac. Sci. Technol. A Vacuum, Surfaces, Film, 1985, 3, 2411-2414.

[25] Zamoume O., Thibault S., Regnié G., Mecherri M.O., Fiallo M., SHARROCK P., Macroporous calcium phosphate ceramic implants for sustained drug delivery, Mater. Sci. Eng. C., 2011, 31, 1352-1356. 